\title{
REAL-TIME FRICTION TORQUE ESTIMATION ON A DIESEL ENGINE USING THE CRANKSHAFT SPEED FLUCTUATION
}

\author{
Seddak Mohammed ${ }^{1,3 *}$ - Lakhdari A. Amina ${ }^{2}$
}

\begin{abstract}
${ }^{1}$ Mechanical Engineering Department, Mechanical Faculty, Université des Sciences et de la Technologie d'Oran Mohamed Boudiaf, BP 1505 El Mnaouar،, Oran 31000, Algérie.

${ }^{2}$ Mechanical Engineering Department, Mechanical Faculty, Université des Sciences et de la Technologie d'Oran Mohamed Boudiaf, BP 1505 El Mnaouar‘, Oran 31000, Algérie.

${ }^{3}$ Laboratoire de recherche en Technologies de l'Environnement, Ecole Nationale Polytechnique d'Oran Maurice Audin, Oran, Algérie.
\end{abstract}

\begin{tabular}{|c|c|}
\hline ARTICLE INFO: & Abstract: \\
\hline $\begin{array}{l}\text { Article history: } \\
\text { Received: } 20.9 .2019 . \\
\text { Received in revised form: } 8.1 .2020 . \\
\text { Accepted: } 8.1 .2020 . \\
\text { Keywords: }\end{array}$ & $\begin{array}{l}\text { Under the pressure of stricter regulations on pollutant emissions } \\
\text { and the desire of users for lower fuel consumption and more } \\
\text { comfortable driving, engine control based on torque has been } \\
\text { developed. To provide an accurate estimate of effective torque, } \\
\text { friction losses must be modeled. The details of a model that }\end{array}$ \\
\hline $\begin{array}{l}\text { Diesel engines } \\
\text { Instantaneous Friction Torque } \\
\text { Crankshaft Dynamic } \\
\text { Thermodynamic model } \\
\text { Instantaneous engine speed } \\
\end{array}$ & $\begin{array}{l}\text { predicts the total instantaneous friction torque for compression } \\
\text { ignition engines are described. The model is based on a } \\
\text { combination of the dynamic model of the crankshaft and the } \\
\text { thermodynamic model. The total instantaneous friction torque is } \\
\text { determined using the instantaneous measurements or numerical }\end{array}$ \\
\hline DOI: https://doi.org/10.30765/er.1515 & $\begin{array}{l}\text { predictions of the gas pressure in the combustion chamber, the } \\
\text { rotational speed of the crankshaft and the load torque. The } \\
\text { experimental data and the numerical simulation results were } \\
\text { compared. The comparison between the different variables shows } \\
\text { a good agreement between the simulation and the experimental } \\
\text { results. }\end{array}$ \\
\hline
\end{tabular}

\section{Introduction}

Rapid improvements in performance and computational capabilities have led to major breakthroughs in many technological areas, especially in the last two decades. With the help of current computers and codes, large-scale mechanical models can be analyzed more efficiently and reliably. Research areas that have benefited greatly from these advances are engine dynamics and thermodynamics, mainly because of their practical importance and the great interest of the automotive industry to reduce production costs. On the other hand, the analysis and measurement of the friction losses in the engine have not yet been satisfactorily solved.

The difficulty lies, on the one hand, in the direct, accurate measurement and, on the other hand, in the interpretation of the complex interactions of the various parameters. The difficulties in analyzing and predicting the total friction losses result from the fact that the total loss in an engine is composed of the losses of different engine parts that do not respond in the same way to changes in pressure, speed and load [1]. The control of these losses is therefore of immediate practical importance. Low friction enables the engine to run at high speed and develop great power. Reduction of friction losses improves the performance parameters of the engine.

The three main components of Engine friction are: rubbing friction, pumping losses (or gas exchange losses), and ancillary losses. Ancillary losses are caused by the drive of engine auxiliaries such as water, oil and fuel pumps. There are various methods of measuring the power lost due to friction in an engine. They can be classified into 4 groups [2]:

\footnotetext{
* Corresponding author.

E-mail address: m_seddak@univ-usto.dz
} 
1) The Willans method

This method consists in drawing a curve giving the specific consumption as a function of the Mean Effective Pressure (MEP) at a fixed speed. The extrapolation of the curve obtained in the range of negative MEP then allows the power lost due to friction to be determined. This method of measuring the Mean Effective Pressure (BMEP) poses virtually no experimental problem. However, extrapolation can be difficult as the curve obtained is not a straight line.

2) Motoring tests

In this method, the engine is driven without combustion by means of an electric motor whose power consumption is measured at the desired speed. The power of the electric motor also includes the transmission losses. However, this measurement only takes into account the effect of speed on friction. Moreover, the results obtained are difficult to extrapolate to a normally running motor, where the variations of the load must be taken into account and the thermal equilibrium of the loaded motor must be reached.

3) The Morse T test

This method [3] consists in measuring the power lost by friction of an engine running by successively eliminating the combustion in each cylinder, either by switching off the spark plug in the case of a spark ignition engine or the injector in the case of a diesel engine. This method has the disadvantage of altering the thermal equilibrium of the engine if the pause is too long or if the engine is stopped to disconnect the spark plug or injector.

4) The indicator method

This method consists, on the one hand, in calculating directly the indicated work (Wi) in order to measure simultaneously the gas pressure of the combustion and the volume it occupies at any time, and, on the other hand, in measuring the effective work (We) by the brake placed at the end of the shaft. The mechanical losses due to friction are then equalto the difference of these two works.

Two categories of models for calculating engine friction are described in the literature: Crankshaft Resolved Models and Mean Cycle Correlations. The first models allow an instantaneous evaluation of friction losses at any point of the engine cycle. They can be divided into models that use analytical and semiempirical correlations and models derived from first principles to solve the Reynolds equation of lubrication [4]. The authors [5] studied models of instantaneous friction in which the various friction components are calculated using measurements of cylinder pressure and engine speed. In this case, the analytical equations were used.

A friction model was based on a study [5] to investigate the effects of maximum cylinder pressure on engine friction. A large effect of load and speed on the mean effective friction pressure (FMEP) was investigated, as the effect of combustion pressure was relatively small. This is attributed to the fact that the engine friction torque is only affected by the maximum cylinder pressure around the TDC position [6]. The values obtained from the engine FMEP (averaged over one cycle of the engine) agree well with the measured values. A semi-empirical correlation was also determined, taking into account the influence of engine speed (Vp: the average piston speed), indicated mean effective pressure (IMEP) and maximum cylinder pressure (Pmax).

Thring [7] studied the effects of design changes on friction in a two-liter four-cylinder gasoline engine. The model was obtained from first principles and for fitting the empirical constants. In reference [7], the boundary friction at the end of stroke was neglected for the entire piston, due to the relatively low speed of the piston and hence the low power dissipation associated with these points in the engine cycle. The bearing form ratio changes resulted in a significant reduction in friction, particularly in the valve train. The changes to the camshaft bearings reduced the overall engine friction by $2.5 \%$, and a maximum reduction of $1 \%$ was achieved with the changes to the main bearing design.

The predictions of a significant increase in friction due to higher cylinder pressures, especially for piston rings and main bearings [7], are in contrast with the results reported by [6] on the effects of maximum cylinder pressure. On the other hand, the authors of reference [8] have performed experimental measurements showing that the friction of the main bearings averaged over one cycle is almost independent of the load.

The engine load has a significant effect on the bearing friction, but only on a small part of the engine cycle. However, the load determines the size of the bearing, which has a strong influence on friction. The work [9] showed that the tension on the piston ring and the cylinder pressure have a negligible effect on the 
friction of the piston. Leong related the latter to the small area behind the rings that is subjected to increased gas load.

The majority of researchers believe that the effect of engine load on FMEP is small [10,11]. A model of instantaneous friction was developed by [12]. This model is able to predict the thickness of the oil film on the friction surfaces and the transition between different lubrication states. The author of reference [12] adopted this approach for the assembly of pistons, but for sliding bearings he used analytical solutions developed by [13].

The author of reference [14] proposed a formulation for the calculation of the frictional torque of the valve set and a model for the friction of the crank of a diesel engine. The equations of the model are analytically derived and are based on dynamic analysis and the Reynolds equation. The model takes into account the variation of the viscosity of the oil. To simulate the unsteady behavior of the engine, models of friction and engine dynamics as a function of crankshaft angle are used in [14]. These models are used for on-line diagnostic and control applications [15]. On the other hand, these models based on crankshaft angle require the determination of many parameters and constants that can be difficult to determine. The comparisons of engine performance simulations with both types of friction models (crankshaft angle and averaged models) show little difference in the predictions of temperature, pressure ... [16].

Engine friction is composed of friction components that are independent of engine speed (boundary friction), those that are proportional to the driving mode (hydrodynamic friction) and finally those that are proportional to the square of the engine speed (turbulent dissipation). The models developed by $[17,18]$ are typical examples of this type of models. A comparison between the predictions of friction of 10 different models applied to a four cylinder direct injection four stroke diesel engine. The large difference between the results shows how difficult it is to obtain consistent friction predictions. However, the study [16] explains that most of the formulas cannot be directly compared because they were derived for different engines and different operating conditions (diesel or gasoline, single or multi-cylinder configurations, driving conditions or ignition, including or excluding pumping losses, etc.).

The authors of reference [19] have shown that the total engine friction has decreased by 15 to $20 \%$ over a period of 20 years, which is due to the reduction of piston friction and pumping losses. To predict friction losses at cooler temperatures, a calibration of lubricant viscosity with temperature was added. A modified version of Patton's model was also developed by [20]. The models developed to describe the internal combustion engine cycle are generally divided into two main groups, depending on the physical basis on which the fundamental equations are established. These are models of thermodynamics and fluid dynamics. In thermodynamic models, the terminology of single-zone and multi-zone zero-dimensional model is often used. Single-zone models are based on the conservation equations for mass and energy, use the first law of thermodynamics, and no spatial resolution because all thermodynamic properties are considered to be uniform. Only one control volume is considered. In multi-zone models, the combustor is divided into multiple zones, with uniform thermodynamic properties for each zone. The first law of thermodynamics applies to each of these control volumes with appropriate boundary conditions. The mathematical equations are a set of differential equations whose independent variable is the time or angle of the crankshaft. The quasi-dimensional models are a special type of these models.

The fluid dynamics models are also known as CFD (Computational Fluid Dynamics) models. They are multidimensional models based on the solution of the conservation equations for mass, momentum and energy at any point on the engine cylinder. To these equations are added transport equations describing the chemical species under consideration. Mathematically, all these equations represent a system of partial differential equations. Time and space coordinates are considered as independent variables, therefore it is possible to obtain a complete spatial resolution of the properties of the gases in the cylinder.

In this work, the dynamic and thermodynamic models of the engine are combined and a model is developed and used to predict the variations of the total instantaneous friction in an engine cycle as a function of the crankshaft angle. The thermodynamic model is used to predict the cylinder pressure. This model handles the conservation equations for energy and mass with the submodels for combustion and heat transfer. The calculations in the cycle are performed for each crankshaft angle. The conservation equations for mass and energy, the property relations, and the laws of perfect gases are solved in the crankshaft angle domain. A single-zone combustion model is used to simulate the theoretical fuel combustion rate. The cylinder is considered as a single control volume, and the temperature and pressure are homogeneous. 
The dynamic model of the engine is based on the analysis of the instantaneous changes in the angular velocity of the crankshaft resulting from the combination of the pressure generated by the combustion gases, the inertia of the moving parts and the applied load. This allows the total instantaneous frictional torque in the engine to be determined.

An examination of the total instantaneous friction should provide a better understanding of the phenomenon of friction in order to reduce it where it is most important.

\section{Modeling}

In this study, the throttle torque is estimated without resorting to the measurement of the cylinder pressure, since the measurement of this quantity is difficult. The idea is to use a fast and accurate thermodynamic model. The innovative idea in this work is to calculate the specific heat ratio $\gamma$ of the thermodynamic processes at each degree of the crankshaft. The overall differential of the cylinder pressure equation is:

$$
\frac{d p_{c y l}}{d \theta}=\frac{\gamma\left(T_{c y l}\right)}{V_{c y l}} \frac{d V_{c y l}}{d \theta} p_{c y l}+\frac{\gamma\left(T_{c y l}\right)-1}{V_{c y l}} \frac{d Q}{d \theta}
$$

Where, $\gamma=\frac{c_{p}}{c_{v}}$ and $R_{g}=C_{p}-C_{v}$

The net heat release is:

$$
\frac{d Q}{d \theta}=\frac{d Q_{\text {in }}}{d \theta}-\frac{d Q_{\text {ioss }}}{d \theta}
$$

where $\frac{d Q_{\text {in }}}{d \theta}$ is the rate of the heat input, $\frac{d Q_{\text {loss }}}{d \theta}$ is the rate of heat loss through cylinder walls.

The total of heat input to the cylinder of fuel in one cycle is:

$$
Q_{i n}=m_{f} L H V
$$

with a dual Wiebe function we can calculate the heat release $\frac{d Q_{\text {in }}}{d \theta}[21]$ :

$$
\begin{gathered}
\frac{d Q_{\text {in }}}{d \theta}=a\left(\frac{Q_{p}}{\theta_{p}}\right) m_{p}\left(\frac{\theta}{\theta_{p}}\right)^{m_{p}-1} \exp \left(-a\left(\frac{\theta}{\theta_{p}}\right)^{m_{p}}\right) \\
+a\left(\frac{Q_{d}}{\theta_{d}}\right) m_{d}\left(\frac{\theta}{\theta_{d}}\right)^{m_{d}-1} \exp \left(-a\left(\frac{\theta}{\theta_{d}}\right)^{m_{d}}\right)
\end{gathered}
$$

where $d$ and $p$ refer to diffusion and premixed phases of combustion. The parameters $\theta_{p}$ and $\theta_{d}$ represent the duration of the premixed and diffusion combustion phases. Also, $Q_{p}$ and $Q_{d}$ represent the integrated energy release for premixed and diffusion phases respectively. The constants are $a=6.9, m_{p}=4$ and $m_{d}=1.5$.

The rate of the heat loss is:

$$
\frac{d Q_{\text {loss }}}{d \theta}=h A_{h}(\theta)\left(T_{c y l}-T_{w}\right) \frac{1}{\omega}
$$

The Woschni model is used to calculate the convective heat transfer coefficient [22, 23]:

$$
h=3.26 D^{-0.2} p^{0.8} T_{\text {cyll }}{ }^{-0.55} \omega^{0.8}
$$


where

$$
\omega(\theta)=2.28 \bar{U}_{p}+C_{1} \frac{V_{d} T_{g r}}{p_{r} V_{r}}\left(p(\theta)-p_{m}\right)
$$

where

$$
\left\{\begin{array}{c}
C_{1}=0 \text { for compression phase, } \\
C_{1}=0.00324 \text { for combustion and expansion phases }
\end{array}\right.
$$

The operating variables at closing of the intake valve are $V_{r}, T_{g r}$, and $p_{r}$ and $p_{m}$ is the pressure at the same position to obtain the pressure $p$ without combustion (pressure values in cranking). $\overline{U_{p}}$ is calculated as :

$$
\overline{U_{p}}=\frac{2 N S}{60}
$$

The following equations give instantaneous displacement, cylinder volume and area [24]:

$$
\begin{gathered}
x(\theta)=l+r(1-\cos (\theta))+\left(l^{2}-r^{2} \sin ^{2}(\theta)\right)^{1 / 2} \\
V(\theta)=V_{c}+\frac{\pi D^{2}}{4} x(\theta) \\
A_{h}(\theta)=\frac{\pi D^{2}}{4}+\frac{\pi D S}{2}(r+1-\cos (\theta)+ \\
\left.\left(r^{2}-\sin ^{2}(\theta)\right)^{1 / 2}\right)
\end{gathered}
$$

The stroke $(S)$ and crank radius are related by:

$S=2 r$

Sonntag [25] has described an equation of the variation of the specific heats of air in a temperature range between 300 and 3,500 K. The air is assumed as an ideal gas.

$$
\begin{aligned}
& C_{p}=2.506 \times 10^{-11} T_{c y l}{ }^{2}+1.454 \times 10^{-7} T_{c y l}{ }^{1.5}- \\
& 4.246 \times 10^{-7} T_{c y l}+3.162 \times 10^{-5} T_{c y l} 0.5+ \\
& 1.3303-1.512 \times 10^{4} T_{c y l}{ }^{-1.5}+ \\
& 3.063 \times 10^{5} T_{c y l}{ }^{-2}-2.212 \times 10^{7} T_{c y l}{ }^{-3}
\end{aligned}
$$

The fourth-order Runge-Kutta method is used to solve equation (1) and obtain the cylinder pressure. The initial and boundary conditions are: pressure $=P_{0}$ atmospheric pressure and temperature $=T_{0}$ ambient temperature.

The state equation is used to calculate the gas temperature in the cylinder:

$$
T_{c y l}=\frac{p_{c y l}(\theta) V(\theta)}{m_{c y l} R_{g}\left(T_{c y l}\right)}
$$




\section{Engine Crankshaft Dynamic Model}

The dynamic model of the engine that we operate must be capable of predicting the indicated torque according to the instantaneous speed of the crankshaft and the load torque applied to the engine shaft. The average speed of the crankshaft is constant during an engine cycle; however, the instantaneous speed exhibits marked fluctuations in view of the sudden variations in the pressure in the cylinder and the forces acting on the piston. Also, to best describe these variations, it is better to define the model in the angular domain.

The rigid body model is a simple model and will require less computation time. This model is used to calculate the total torque. The equilibrium equation describes the crankshaft torque $[26,27,28]$ :

$$
\begin{aligned}
I(\theta) \ddot{\theta}=T_{\text {total }}(\theta)= & T_{\text {gas }}(\theta)+T_{\text {mass }}(\theta)+ \\
& T_{\text {load }}(\theta)+T_{f r}(\theta)
\end{aligned}
$$

Reciprocating mechanisms have variable inertia due to the change of geometry through a crank revolution. The moment of inertia is [26]:

$$
I(\theta)=m_{r o t} \cdot r^{2}+m_{o s c} \Sigma_{j=1}^{z_{c y l}}\left(\frac{d x}{d \theta}\right)^{2}
$$

In study [26] a two-mass approach is presented as a model of the connecting rod. The oscillating mass at each cylinder is:

$$
m_{\text {osc }}=m_{\text {piston }}+m_{\text {cre }} \frac{l_{\text {ose }}}{l}
$$

with $l_{\text {ose }}=\frac{2 l}{3}$

and the rotational mass of the crankshaft portion at one cylinder

$$
\frac{m_{\text {rot }}}{z_{c y l}}=\frac{m_{\text {crank }}}{z_{c y l}}+m_{c r} \frac{l_{\text {rot }}}{l}
$$

with $l_{\text {rot }}=\frac{l}{3}$

The indicated torque $T_{\text {indicated }}$ or $T_{g a s}$ is a function of the pressure $p$ and the geometry of the engine. This torque is expressed as:

$$
\begin{aligned}
& T_{\text {gas }}(\theta)=\left(p_{\text {cyl }}(\theta)-p_{0}\right) A_{p} \frac{d x}{d \theta}= \\
& p_{\text {gas }}(\theta) A_{p} \frac{d x}{d \theta}
\end{aligned}
$$

The gas pressure is defined as $P_{g a s}=p_{c y l}(\theta)$ - $p_{0}$.

$p_{0}$ : the counteracting pressure $\left(p_{0=} p_{a t m}\right)$

The engine reciprocating components motion (piston and connecting rod) generates the mass torque $T_{\text {mass }}$ or reciprocating torque:

$$
\begin{aligned}
& T_{\text {mass }}(\theta, \dot{\theta}, \ddot{\theta})=-\left(m_{\text {piston }}+m_{c r}\right) \frac{d x}{d \theta} \frac{d^{2} x}{d \theta^{2}} \dot{\theta}^{2}- \\
& \left(m_{\text {piston }}+m_{c r}\right)\left(\frac{d x}{d \theta}\right)^{2} \ddot{\theta}
\end{aligned}
$$

where $m_{c r}$ and $m_{\text {piston }}$ are connecting rod and piston mass, the functions $\frac{d x}{d \theta}$ and $\frac{d^{2} x}{d \theta^{2}}$ are the first and second derivative of stroke (displacement) of piston respectively.

The derivatives of the piston displacement are: 


$$
\begin{gathered}
V_{p}=\frac{d x}{d \theta}=r\left(\sin (\theta)+\frac{r}{l} \cdot \frac{\sin (\theta) \cos (\theta)}{\sqrt{1-\frac{r^{2}}{I^{2}} \sin ^{2}(\theta)}}\right) \\
\frac{d^{2} x}{d \theta^{2}}=r\left(\cos (\theta)+\frac{\frac{r}{1}\left(\cos ^{2}(\theta)-\sin ^{2}(\theta)\right)+\frac{r^{2}}{\Gamma^{2}} \sin ^{4}(\theta)}{\left(\sqrt{1-\frac{r^{2}}{I^{2}} \sin ^{2}(\theta)}\right)^{8}}\right)
\end{gathered}
$$

$T_{\text {load }}$, in equation (22), is the load (resistance) torque, which is usually expressed by:

$$
T_{\text {load }}(\theta)=c+k \omega^{s}
$$

$\omega$ : Angular velocity $\left(s^{-1}\right)$

For a linear load (electric brake, generator), $c=0$,

$k>0$ and $s=1$ [29].

Equation (23) is the result of the left-side integration of equation (14), $\left.\dot{\theta}\right|_{\theta}$ indicates the instantaneous crankshaft speed for the crank angle $\theta$.

$$
\begin{aligned}
& \int_{\theta-\Delta \theta}^{\theta} J \ddot{\theta} d \theta=J \times \int_{\theta-\Delta \theta}^{\theta} \frac{d \dot{\theta}}{d t} d \theta= \\
& I \times \int_{\theta-\Delta \theta}^{\theta} \frac{d \theta}{d t} d \dot{\theta}=J \times \int_{\theta-\Delta \theta}^{\theta} \dot{\theta} d \dot{\theta}= \\
& \frac{1}{2} J\left[\left(\left.\dot{\theta}\right|_{\theta}\right)^{2}-\left(\left.\dot{\theta}\right|_{\theta-\Delta \theta}\right)^{2}\right]
\end{aligned}
$$

The equation (24) shows the right side of equation (14) integration. The instantaneous torque at this specific crank angle is assumed to be almost constant when the interval $\Delta \theta$ is sufficiently small. In this study, $\Delta \theta=1^{\circ}$ $C A D$ (Crankshaft Angular Degree).

$$
\begin{gathered}
\int_{\theta-\Delta \theta}^{\theta} T_{\text {total }}(\theta) d \theta= \\
\frac{T_{\text {total }}(\theta-\Delta \theta)+T_{\text {total }}(\theta)}{2} \times \Delta \theta=\bar{T}_{\text {total }}(\theta) \times \Delta \theta
\end{gathered}
$$

The total torque is given as:

$$
\bar{T}_{\text {total }}(\theta)=\frac{1}{2} \times \frac{J}{\Delta \theta}\left[\left(\left.\dot{\theta}\right|_{\theta}\right)^{2}-\left(\left.\dot{\theta}\right|_{\theta-\Delta \theta}\right)^{2}\right]
$$

Finally, total instantaneous friction torque is given by:

$$
\begin{gathered}
T_{f r}(\theta)= \\
T_{\text {total }}(\theta)-T_{\text {gas }}(\theta)-T_{\text {mass }}(\theta)-T_{\text {load }}(\theta)
\end{gathered}
$$

Through the operation of the measure of the instantaneous speed of the crankshaft using a proximity sensor we can deduce the total torque of the crankshaft. Thus, it becomes possible to estimate the friction torque and drive axillaries (so-called parasitic couples) in steady state if the resistant torque applied to the engine is known. 


\section{Simulation and Experimental Results}

The first part of this paper is devoted to the simulation results of the cylinder pressure of the K9K diesel engine. A comparison is made between the measured results and those obtained with a thermodynamic model. The second part is devoted to the presentation of the results of the simulation series derived from the model of engine dynamics in order to obtain the different torques acting on the entire crankshaft. The different torques are:

- the total torque calculated from the fluctuation of the measured rotational speed of the crankshaft,

- the moment of inertia (mass torque),

- the indicated torque (couple of gas),

- the total instantaneous friction torque.

\subsection{Cylinder pressure result}

Figure (2) shows a comparison between the cylinder pressure calculated and measured during an engine cycle for more details see [30]. The results are obtained by simulation for different engine operating conditions:

a) $1100 \mathrm{rpm}$ at load of $67.5 \mathrm{Nm}$,

b) $1400 \mathrm{rpm}$ at load of $121 \mathrm{Nm}$,

c) $1700 \mathrm{rpm}$ at load of $166.3 \mathrm{Nm}$.

It can be noted that the experimental measurements values are in the order of those given by the numerical values predicted by the model. These results show that the following deviations:

Table 1. Engine specifications [30].

\begin{tabular}{|l|c|c|}
\hline \multicolumn{1}{|c|}{ Parameters } & Specifications & Unit \\
\hline Engine type & K9K & \\
\hline $\mathrm{N}^{\circ}$ of cylinders & Four cylinders & \\
\hline $\mathrm{N}^{\circ}$ of strokes & Four strokes & \\
\hline Max. power & 80 & $\mathrm{~kW}$ \\
\hline Max. torque & 240 & $\mathrm{Nm}$ \\
\hline Cylinder bore & 76 & $\mathrm{~mm}$ \\
\hline Bowl depth & 14 & $\mathrm{~mm}$ \\
\hline Stroke length & 80.5 & $\mathrm{~mm}$ \\
\hline Compression ratio & 15.3 & \\
\hline
\end{tabular}

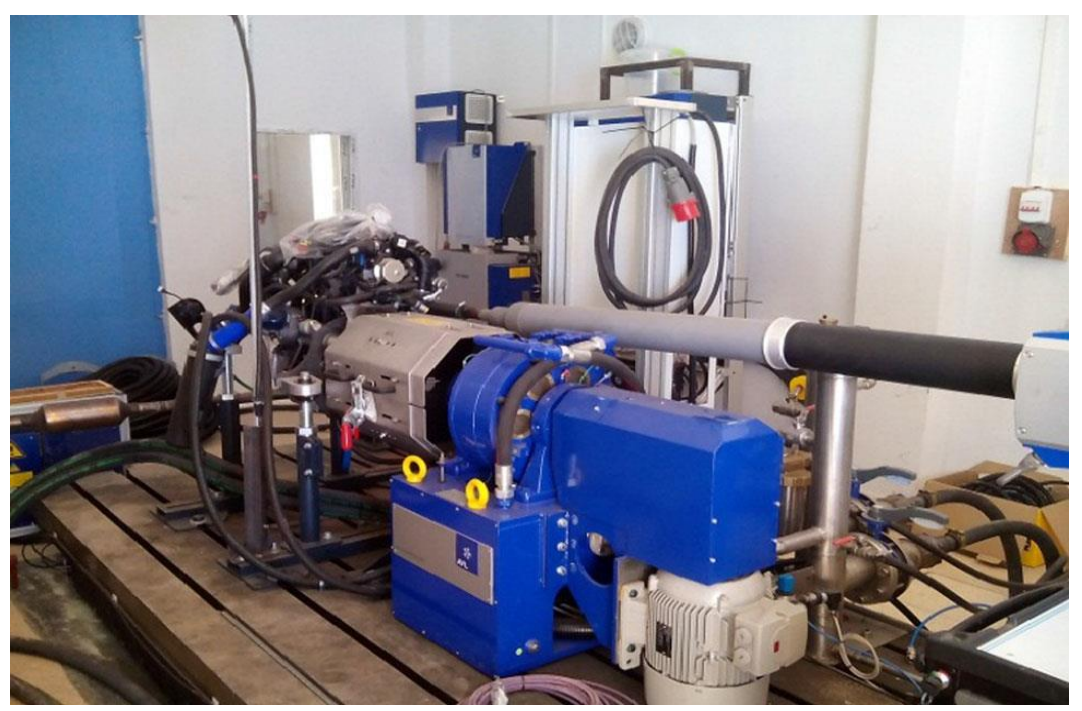

Figure 1. View of the engine test bench [30]. 
- for $1100 \mathrm{rpm}$ the peak-to-peak difference is $1.6 \%$ with a delay of 1 degree,

- for $1400 \mathrm{rpm}$ the peak-to-peak difference is $2 \%$ with a delay of 3 degrees,

- for $1700 \mathrm{rpm}$ the peak-to-peak difference is $4.2 \%$ with a delay of 1 degree.

Most prediction errors are due to simplifying assumptions. Nevertheless, the model can be considered sufficiently accurate for control analysis. The numerical results of the cylinder pressure are then integrated into the dynamic model (second part) to estimate the total lost instantaneous frictional torque described by equation (26).

\subsection{The dynamic model}

Figure (3) shows the flow chart for estimating the friction torque. In this method, first the total torque applied to the crankshaft is estimated using the rotational speed measured by the dynamic model. Then the gas, inertia and load torques are subtracted.

The measured angular velocity data contains high frequency components. These frequency components are due to the high frequency torsional vibrations of the crankshaft at various natural frequencies and random noise from unknown sources. To resolve the equations required to calculate the various torques, the angular velocity data must be differentiated once to determine the angular acceleration.

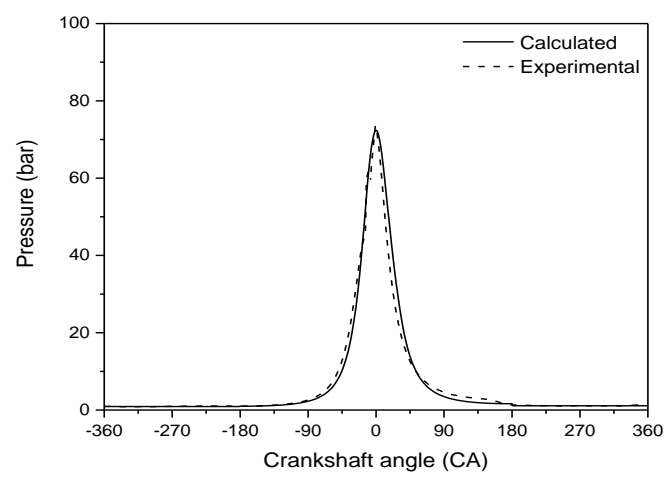

a)

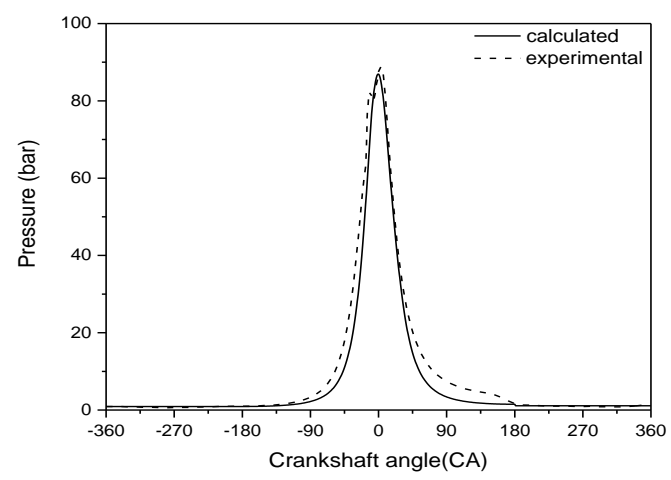

b)

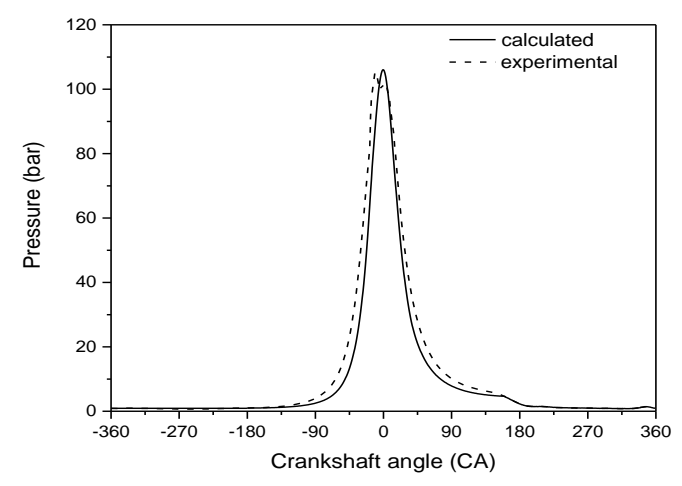

c)

Figure 2. Comparison between measured and simulated in-cylinder pressure. 


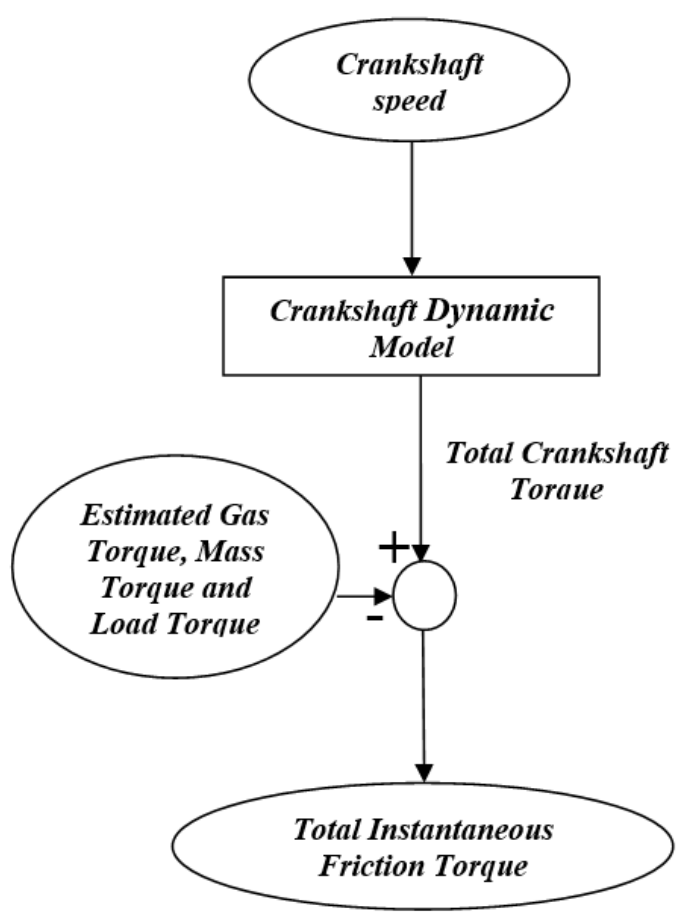

Figure 3. The flowchart of the estimation algorithm.

If the raw data (gross speed signal) were used for the calculation, the high-frequency components would be greatly magnified by the subsequent differentiation of angular velocity. Therefore, the high-frequency components are filtered before differentiation to increase the signal-to-noise ratio when resolving the torque equations. The Fast Fourier Transform (FFT) filter with a 12-point window was used as the filtering method in this study. The filter allowed us to separate between the higher order torsional vibration components and the lower frequency components of interest (Figure 4). The moment of inertia of the engine is shown in Figure (5). The inertia of the crank mechanism is not constant but a function of the crankshaft angle. Since the large end of the connecting rod is attached to the crankshaft, the maximum of the crank inertia is near and angular position of the crankshaft and the minimum is near 0 and $\pi$. Figure (6) illustrates the evolution of the instantaneous crankshaft acceleration under steady-state conditions. The crankshaft velocity measured after filtering was used to calculate the instantaneous acceleration.

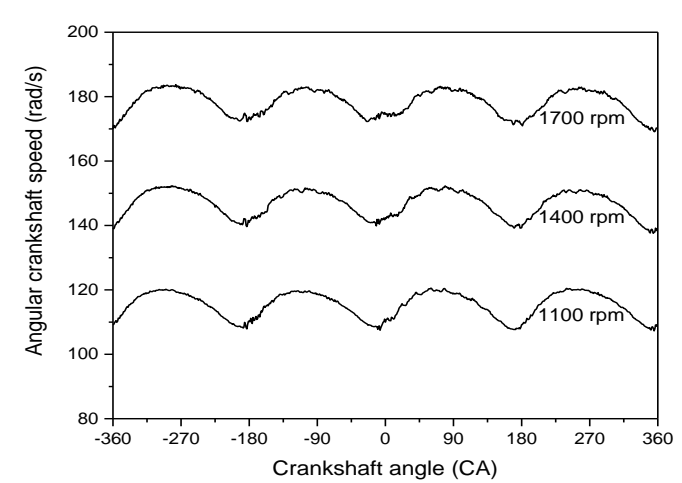

a)

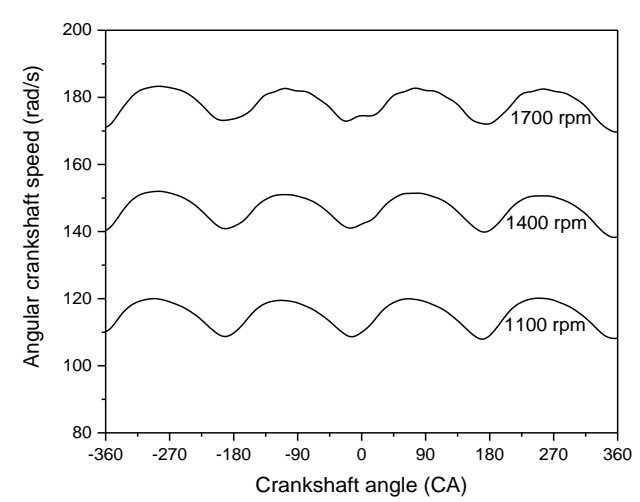

b)

Figure 4. Instantaneous crankshaft speed: a) measured signal and b) filtered signal. 
The torque of inertia (of mass), $T_{\text {mass }}$, is the resultant of the reciprocating movement of the piston and the head of the connecting rod (part of the connecting rod connected to the piston which describes a translation movement). Figures (7.a) and (7.b) respectively represent the variation of the mass torque of the fourth cylinder, as well as the changes in the total mass torque obtained by adding all the mass torque of all the cylinders as a function of the crankshaft angle for the three operating conditions. The moment of inertia (mass torque) is proportional to the speed of rotation of the motor. The expression for the square of the speed in the mass torque expression (Equation 19) increases rapidly as the speed of the motor increases. Therefore, at high speeds, this term will amplify the mass torque and make it much more influential in determining the total torque of the crankshaft.

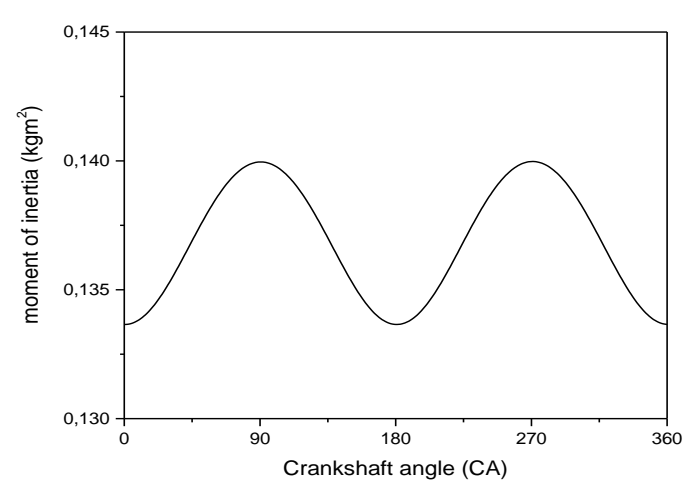

Figure 5. Inertia of the crankshaft assembly.

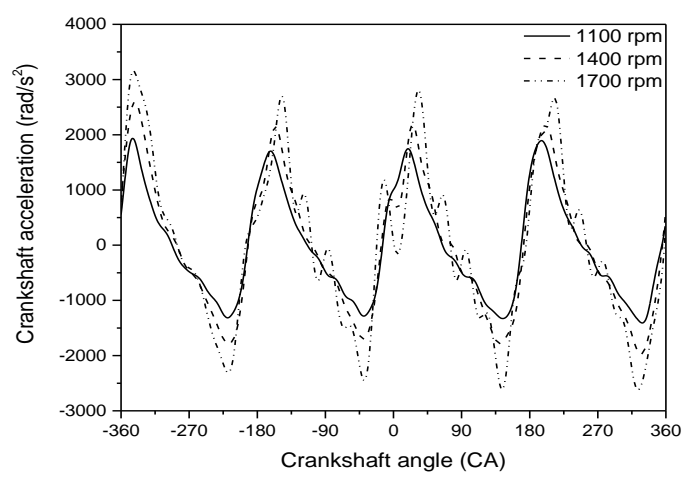

Figure 6. Estimation of instantaneous filtered acceleration of crankshaft.

The indicated torque, $T_{\text {gas }}$, is the result of the action of the gases on the piston. It translates the thermodynamic work transmitted to the crankshaft. Figure (8) shows the variation of the indicated torque calculated for each cylinder depending on the crank angle of rotation. The torque is negative, during the intake and compression strokes (between $-360^{\circ}$ and $0^{\circ}$ ). It increases considerably during the relaxation, following the high pressure of the combustion gases in the cylinder, which in turn generates significant forces on the piston. During the exhaust process, the torque decreases to become negative.

The indicated torque of the fourth cylinder plotted according to the measured cylinder pressure is compared with the calculated indicated torque of the same cylinder. It can be noted that the torque obtained by the calculation coincides well with the measured torque. The difference between the two curves and especially at the top is due to the difference between the pressure values measured and predicted by the thermodynamic model. 


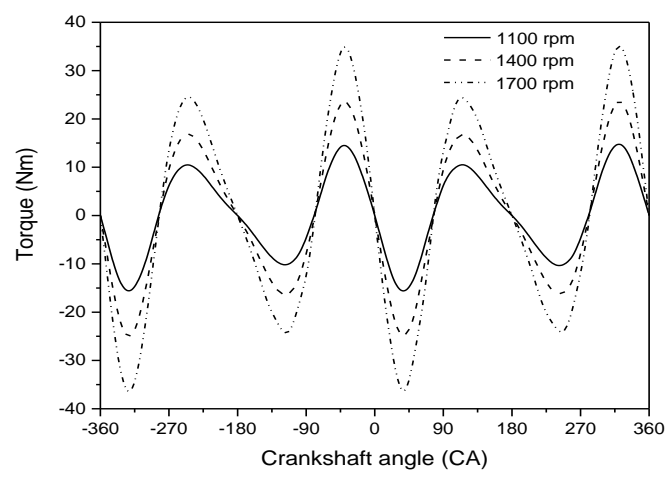

a)

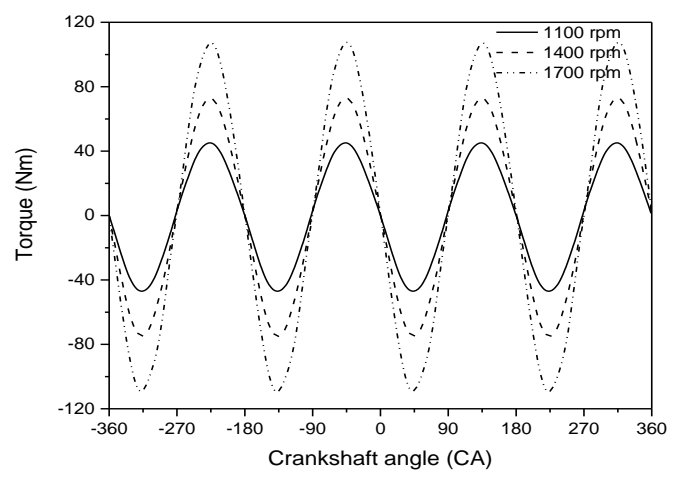

b)

Figure 7. Variation of mass torque; a) individual cylinder and b) total mass torque.

The sum of the indicated torques corresponding to each cylinder gives us the total torque indicated. $T_{\text {total gas }}(\theta)=\Sigma_{1}^{Z_{c y l}=4} T_{g a s}(\theta)$. These pairs are shown in Figure (9) for the three working engine speeds considered. A good agreement is observed between the total torque indicated established from the cylinder pressure prediction and that obtained from the measured cylinder pressure. The absolute difference is less than $10 \%$ due to the normal difference between calculated and measured cylinder pressures.
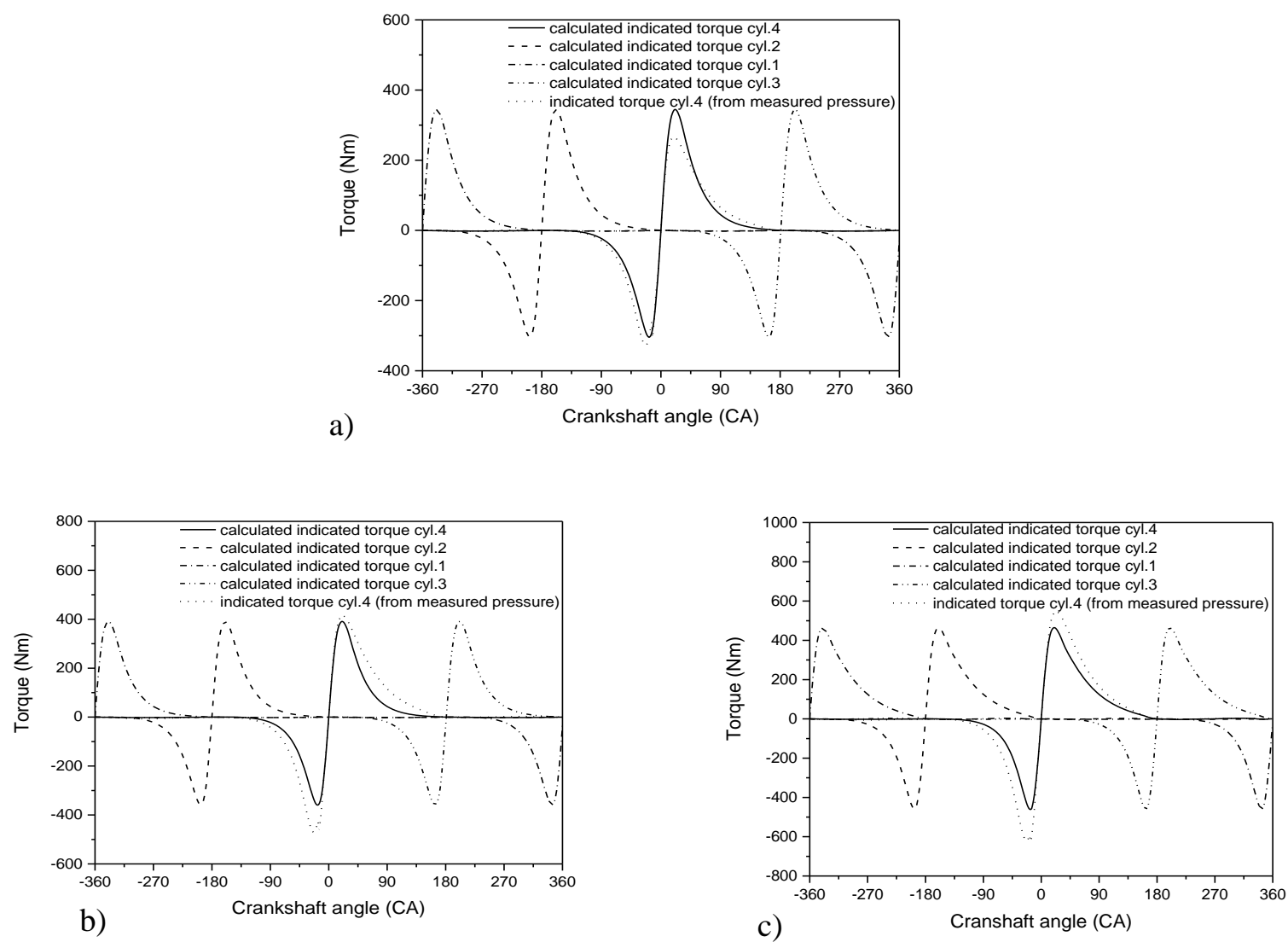

Figure 8. Comparison between measured and predicted gas torque for the fourth cylinder. 
Figure (10) shows the comparison between the total torque obtained from the measurement of the instantaneous speed of the crankshaft for the three operating conditions. The total torque is proportional to the speed of rotation.

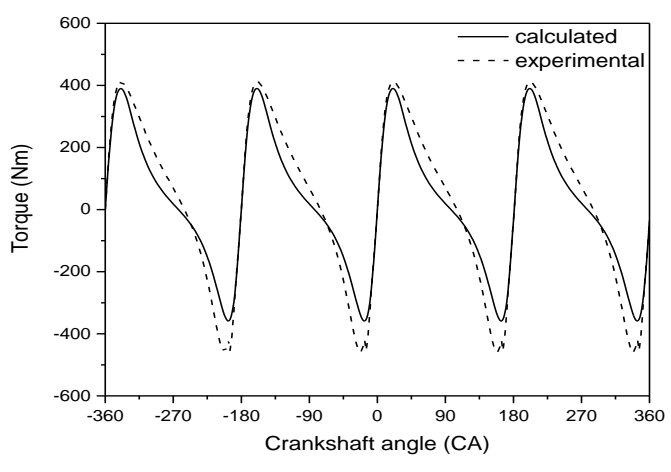

a)

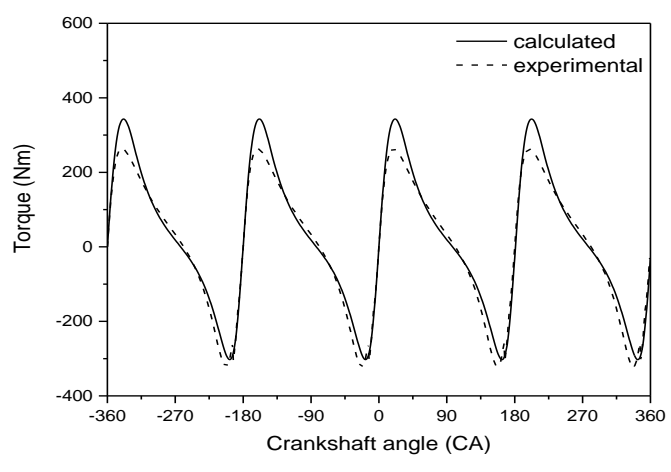

b)

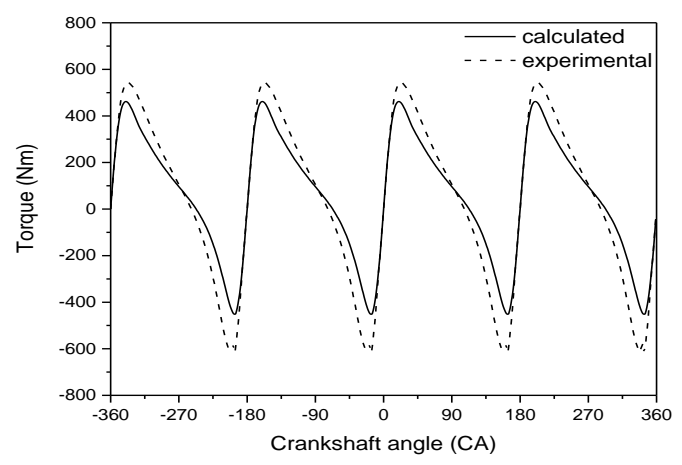

c)

Figure 9. Comparison between measured and predicted of the engine total indicated (gas) torque.

It must be realized that the load torque exhibits fluctuations in an engine cycle even under the stationary conditions. An example of the instantaneous measurement of the load torque for the three speeds of rotation is shown in Figure (11).

Figure (12) shows the total instantaneous friction torque at different rotational speeds of the crankshaft. It also shows that the total friction torque increases with the speed of rotation of the crankshaft.

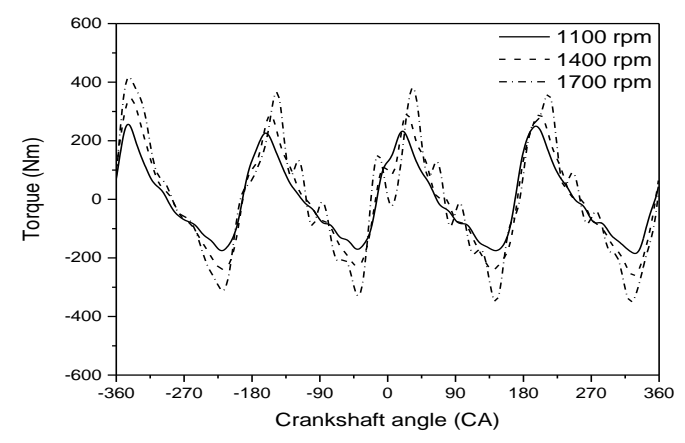

Figure 10. Variation of measured total torque. 


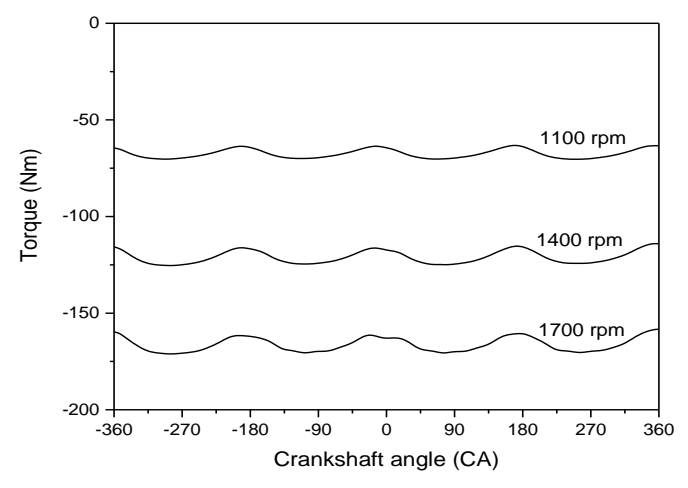

Figure 11. Variation of load torque.

We note that for a given speed this torque is very important in the vicinity of the Top Dead Center (TDC) of each cylinder because of the preponderant effect of the strong cylinder pressure. Indeed, before the TDC, the increase in torque is due to the fact that the pressure of the gases is expressed as a resistance to movement of the piston, and thus causes an increase in the friction torque.

At the $T D C$, the torque passes through a minimum, in fact a piston stopping the friction it generates becomes zero. The total friction torque then becomes equal to that of the drive of the bodies and the friction of the bearings. After the TDC, the increase in the friction torque is due to the fact that one of the cylinders is in the expansion phase.

In regions distant from $T D C$ of the end of compression, the total friction torque becomes substantially constant and low. This is due to the preponderance of the effect of crankshaft rotation speed in these regions.

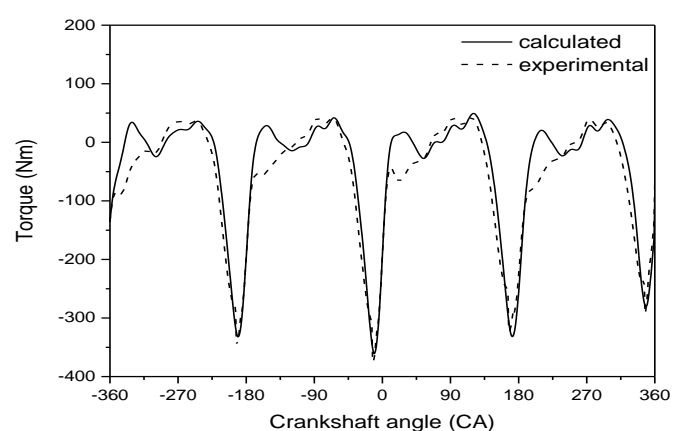

a)

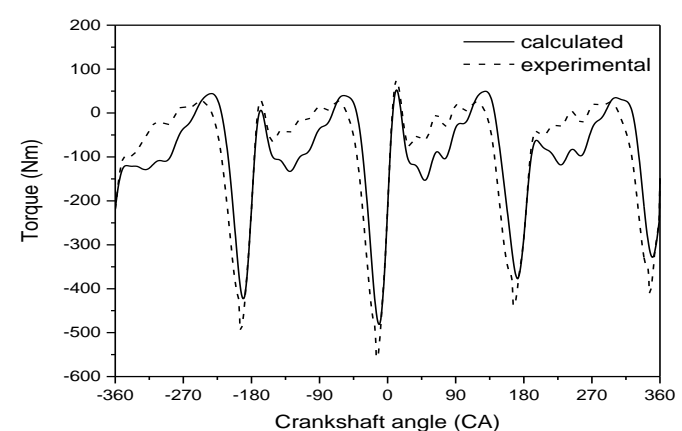

b)

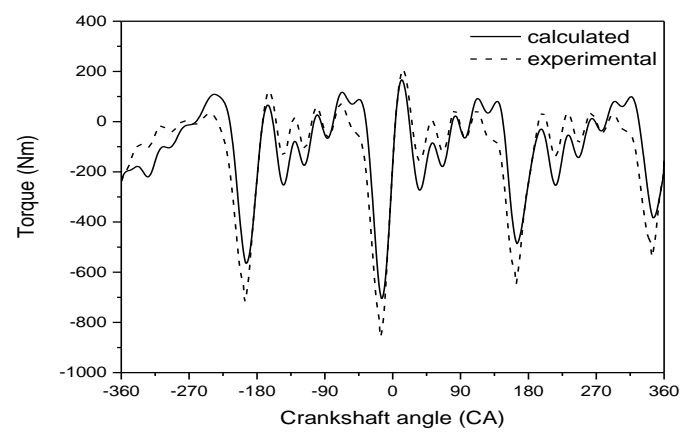

c)

Figure 12. Comparison between measured and predicted of the engine total friction torque. 


\section{Conclusions}

In this study, a method for estimating the total instantaneous friction torque for a four-cylinder engine IC is investigated. The total instantaneous friction torque was calculated based on measurements of the instantaneous angular velocity of the crankshaft and prediction of the cylinder pressure based on a simplified thermodynamic approach.

The dynamic model of a rigid body of the engine crankshaft was used to calculate the total torque as a function of the instantaneous speed of the crankshaft. To estimate the cylinder pressure of the engine, we used a phenomenological model with zero dimension at steady state. By obtaining the total torque, it is possible to obtain the instantaneous friction torque. Then, the numerical simulation was validated with respect to the experimental results. The main conclusions are:

- The inertia variations of the crank shaft assembly are included,

- Profiles of the cylinder gas pressure and the different torques predicted by the model, during steady-state cycles, are in good agreement with measurements,

- The technique is applied to the problem of estimating total instantaneous friction torque from measurements of crankshaft angular velocity and displacement. It is shown that the estimated torque has a good accuracy when compared to experimental data. The results are encouraging indicating promise for real-time applications and for use as an on-board diagnostic tool.

\section{Notations}

$\theta \quad$ Crankshaft angular position, (rad)

$\dot{\theta} \quad$ Instantaneous crankshaft speed, $(\mathrm{rad} / \mathrm{s})$

$\ddot{\theta} \quad$ Instantaneous crankshaft acceleration, $\left(\mathrm{rad} / \mathrm{s}^{2}\right)$

$l \quad$ Connecting rod length, $(\mathrm{m})$

$\gamma \quad$ Specific heat ratio, dimensionless

$A_{p} \quad$ Piston surface, $\left(\mathrm{m}^{2}\right)$

$A_{h} \quad$ Heat transfer area, $\left(\mathrm{m}^{2}\right)$

$D \quad$ Cylinder bore, $(\mathrm{m})$

$J \quad$ Moment of inertia, $\left(\mathrm{kg} \mathrm{m}^{2}\right)$

$L H V$ Lower heating value, $(\mathrm{kJ} / \mathrm{kg})$

$m_{\text {cyl }}$ Mass of in-cylinder mixture, $(\mathrm{kg})$

$m_{f}$ Mass of injected fuel, $(\mathrm{kg})$

$p_{\text {cyl }}$ In-cylinder pressure, (bar)

$r$ Crank radius, (m)

$R_{g} \quad$ Universal gas constant, $(\mathrm{kJ} / \mathrm{kg} . \mathrm{K})$

$T_{\text {cyl }}$ In-cylinder gas temperature, $(\mathrm{K})$

$V_{c y l}$ Cylinder volume, $\left(\mathrm{m}^{3}\right)$

$Q \quad$ Heat transfer, $(\mathrm{kJ})$

$Q_{\text {in }}$ Heat added from burning fuel, $(\mathrm{kJ})$

$Q_{d}$ Integrated energy release for diffusion combustion phases, $(\mathrm{kJ})$

$Q_{\text {loss }}$ Heat losses, $(\mathrm{kJ})$

$Q_{p} \quad$ Integrated energy release for premixed combustion phases, $(\mathrm{kJ})$

$N \quad$ Engine speed, (rpm)

$S$ Engine stroke, (m)

$C_{p} \quad$ Constant pressure specific heat, $(\mathrm{kJ} / \mathrm{kg} \mathrm{K})$

$C_{v}$ Constant volume specific heat, $(\mathrm{kJ} / \mathrm{kg} \mathrm{K})$

$Z_{\text {cyl }}$ Number of cylinders,

$T_{w}$ Cylinder temperature, $(\mathrm{K})$

$V_{c} \quad$ Clearance volume. $\left(\mathrm{m}^{3}\right)$ 


\section{References}

[1] Furuhama, S. and Sasaki, S.: New Device for the Measurement of Piston Frictional Forces in Small Engines, SAE Technical Paper 831284, (1983).

[2] Heywood, J. B: Internal Combustion Engine Fundamentals, McGraw-Hill series in mechanical engineering), 1988.

[3] W. Ball, W. Jackson, N. Pilley, A. and Porter, B.: The Friction of a 1.6 Litre Automotive EngineGasoline and Diesel, SAE Technical Paper 860418, (1986).

[4] Paranjpe, R. and Cusenza, A.: FLARE: An Integrated Software Package for Friction and Lubrication Analysis of Automotive Engines - Part II: Experimental Validation, SAE Technical Paper 920488, (1992).

[5] Ciulli, E., Rizzoni, G. and Dawson, J.: Numerical and Experimental Study of Friction on a Single Cylinder CFR Engine, SAE Technical Paper 960357, (1996).

[6] Kouremenos, D., Rakopoulos, C., Hountalas, D. and Zannis, T.: Development of a Detailed Friction Model to Predict Mechanical Losses at Elevated Maximum Combustion Pressures, SAE Technical Paper, (2001).

[7] Thring, R.: Engine Friction Modeling, SAE Technical Paper 920482, (1992).

[8] Miura, A. and Shiraishi, K.: Investigation of Main Bearing Friction in a Diesel Engine, SAE Technical Paper 890140, (1989).

[9] Leong, D.K.: Investigations of Friction Losses in Automotive Internal Combustion Engines, $\mathrm{PhD}$ Thesis, University of Nottingham, (2004).

[10] Luff, D., Cheng, K. Y., Leong, D., Law, T.,and Shayler, P.J.: Diesel Engine Cold Start - Progress Report 47. (2003).

[11] Owen, N. J., Gilbert, I.P. and Jackson, N.S.: Firing Friction Breakdown of a Ford 1.8L IDI Diesel Engine, Ricardo. (1989).

[12] Livanos, G. and Kyrtatos, N.: A Model of the Friction Losses in Diesel Engines, SAE Technical Paper, (2006).

[13] Hirani, H., Athre, K. and Biswas, S.: Dynamically Loaded Finite Length Journal Bearings: Analytical Method of Solution, ASME Journal of Tribology, 121 (1999), 844-852.

[14] Zweiri, Y. H., Whidborne, J.F. and Seneviratne, L.D.: Instantaneous friction components model for transient engine operation, Proc. Inst. Mech. Engrs., Journal of Automobile Engineering, 214, (1999).

[15] Ma, Q., Rajagopalan, S.S.V., Yurkovich, S. and Guezenec, Y.G.: A High Fidelity Starter Model for Engine Start Simulations, American Control Conference, Portland, 2005, 4423-4427.

[16] Ciulli, E.: A Review of Internal Combustion Engine Losses - Part 1: Specific Studies on the Motion of Pistons, Valves and Bearings, Proc. Instn. Mech. Engrs., Part D, Journal of Automobile Engineering, 206, (1992), 223-236.

[17] Bishop, I.: Effect of Design Variables on Friction and Economy, SAE Technical Paper 640807, (1964).

[18] Patton, K., Nitschke, R. and Heywood, J.B.: Development and Evaluation of a Friction Model for Spark-Ignition Engines, SAE Technical Paper 890836, (1989).

[19] Sandoval, D. and Heywood, J.B.: An Improved Friction Model for Spark-Ignition Engines, SAE Technical Paper, (2003).

[20] Shayler, P. J., Leong, D.K. and Murphy, M.: Friction Teardown Data from Motored Engine Tests in Light Duty Automotive Diesel Engines at Low Temperatures and Speeds. ASME Fall Technical Conference, Erie, 2003.

[21] Iserman, R.: Engine Modeling and Control: Modeling and Electronic Management of Internal Combustion Engines. Springer, Berlin, 2014.

[22] Sakhrieh, A., Abu-Nada, E., Al-Hinti, I., Al-Ghandoor, A. and Akash, B.: Computational thermodynamic analysis of compression ignition engine, Int. Commun. Heat Mass Transf, 37 (2010), 299-303.

[23] Ferguson, C. and Kirkpatrick, A.: Internal Combustion Engines: Applied Thermosciences. Wiley, New York, 2001. 
[24] Pulkrabek, W.: Engineering Fundamentals of the Internal Combustion Engine, 2nd edn. Pearson Prentice-Hall, Upper Saddle River, 2004.

[25] Sonntag, R., Borgnakke, C. and VanWylen, G.: Fundamentals of Thermodynamics, 5th edn. Wiley, New York, 1998.

[26] Kiencke, U., Nielsen, L.: Automotive Control Systems for Engine, Driveline and Vehicle. Springer, London, 2000.

[27] S. Schagerberg, S.: Torque Sensors for Engine Applications. Lic thesis 472L. Chalmers University of Technology, 2003.

[28] Rakopoulos, C.D, Giakoumis, E.G.: Diesel Engine Transient Operation: Principles of Operation and Simulation Analysis. Springer, London, 2009.

[29] Rakopoulos, C.D., Giakoumis, E.G.: Simulation and analysis of a naturally aspirated IDI Diesel engine under transient conditions comprising the effect of various dynamic and thermodynamic parameters, Energy Convers, 39 (1998), 465-484.

[30] Seddak, M. and Liazid, A.: An Experimental Study on Engine Dynamics Model Based on Indicated Torque Estimation, Arab J Sci Eng, 43 (2018). 